\title{
On the Positive View of Marriage and Love in The Bridges of Madison County
}

\author{
Tong Lili
}

\author{
School of Foreign Languages, Dalian Jiaotong University, Dalian, Liaoning, China \\ Elizabeth1998@163.com
}

\begin{abstract}
The novel, The bridges of Madison County, brings people a sad yet beautiful love story. Although it is a novel about extramarital love, it gives readers a lot of enlightenment on love and marriage. From the aspect of marriage and love, the unforgettable love between the hero and the heroine as well as the heroine and her husband's marriage is analyzed in the paper in order to give people insights into the barriers brought about by the boundary between people in the organized society to human emotional expression and communication, advocate to face the emotion and marriage life with a positive attitude, and draw the conclusion of establishing a positive concept of marriage and love.
\end{abstract}

Keywords: Love, marriage, the view of marriage and love.

\section{浅谈《廊桥遗梦》中的积极的婚恋观}

佟丽莉

大连交通大学外国语学院, 大连, 辽宁, 中国

Elizabeth_1998@163.com

\section{摘要}

小说《廊桥遗梦》带给人们了一个真挚、凄美的爱情故事。尽管这是一部描写婚外恋的小说，但它却 给了读者很多对爱情和婚姻的启示。本文从婚恋观的角度，对男女主人公之间的刻骨铭心的爱恋以及 小说中女主人公与她丈夫的婚姻进行分析, 剖析组织化社会中人与人之间界限给人类情感表达、感情 沟通所带来的障碍，主张以积极的态度面对感情和婚姻生活，以得出建立积极婚恋观的结论。

关键词: 爱情; 婚姻; 婚恋观

\section{1. 前言}

1992 年, 美国作家罗伯特・詹姆斯・沃特的小说《廊 桥遗梦》出版面世, 该作品以其对婚外恋情的探讨和对 中年人心理情感的展现受到了读者和评论界的广泛关 注。紧接着又被改编成同名电影, 在观众和读者中引起 了更为广泛的轰动效应。作品描写了女主人公弗朗西斯 卡和男主人公罗伯特在美国乡村短暂邂逅后发生的浪 漫缠绵的爱情故事。在很长时间内, 婚外恋情成为经久 不衰的社会话题。家庭美满的女主人公在丈夫和子女外 出时遭遇她从未预料到的刻骨铭心的爱情, 然而强烈的 家庭责任感让弗朗西斯卡最后做出了艰难选择, 小说深 刻揭示出了中年人的伦理价值观与情感平衡的问题。

\section{2. “突如其来” 的恋情}

与其说男女主人公在麦迪逊乡下罗曼斯桥畔发生 的情感纠葛是一场是 “突如其来” 的恋情, 不如说是这
场恋情是冥冥之中注定必然要发生的。女主人公弗朗西 斯卡的身上有许多非传统的、浪漫的特质。她年轻的时 候曾经和大学艺术系教授有过一段恋情, 憧憬着对爱情 无限的幻想, 她一直向往那烛光重重、觥筹交错、歌舞 曼妙的都市文明。然而这个梦境的实现却受到传统观念 较深的父母的强加束缚, 这段恋情无疾而终。她最终遇 到了丈夫理查德, 仍然怀抱着那不勒斯少女时代梦幻想 法的女主人公, 和理查德来到麦迪逊县, 成家立业, 生 儿育女。

原来研究比较文学, 受浪漫主义影响较深的女主人 公, 转眼间化身麦迪逊乡下的一名农家主妇, “在二十年 的封闭生活中，长期遵循乡村文化所要求的克制、含蓄、 不苟言笑的行为准则的她” 时常在自家前廊的秋千上， 漫不经心地望着公路，似乎在等待和期盼着什么。平淡 的生活、枯燥的家务并没有使这位已进入中年的女性泯 灭少女时代的梦想。而是将这种梦想封存、深埋，像封 存的陈酒, 积蓄的种子, 等待着时机就会迸发出不能压 抑的能量。如同小说中描述的, 她心血来潮时买来的白 兰地一样, 在罗伯特到来之前她一直没有打开那瓶盖。 
仅仅是缺少了一个开启的时机。

从事多年摄影创作的男主人公罗伯特一经出现, 他 丰富阅历让自己形成了独特的气质, 就立即激发了女主 人公深藏在骨子里的激情与梦想。叶芝的诗句 “遥远的 事物才是美” 重燃了弗朗西斯卡因处理家庭琐碎事务久 已麻木灵魂。罗伯特表达谢意的野菊花, 让弗朗西斯卡 心中泛起了一种特别的滋味, 在互相讲述自己婚姻家庭 后告别后, 弗朗西斯卡在夜色中依依不舍, 下决心将字 条留在桥头, 让两人第二天的相见顺理成章。两人相逢 美妙的夜晚、怀旧的音乐将她的蒙尘已久的旧梦唤醒。 站在她面前的自称是 “最后的牛仔”, 被当地人称为 “嬉 皮士” 的罗伯特, 就像是 “骑着彗星尾巴乘风而来落在 她巷子口的什么生物”, 将她深深吸引, 使她又有了 “翩 翩起舞的天地”。这一切的发生, 让她暂时忘记了作为人 妻的责任, 自我意识的觉醒使她完全沉浸在与罗伯特的 爱河之中。心的交流让他们拉近了彼此的距离, 像小说 中描述的一样 “我要向你走去, 你向我走来已经很久了。 虽然我们相会之前谁也不知道对方的存在。” 爱情悄悄 地发生了。

\section{3. “真空的” 爱情}

弗朗西斯卡和罗伯特的爱情产生在近乎一种近似 真空的环境里。故事发生之时, 恰逢弗朗西斯卡的丈夫 理查德带着孩子们去博览会展出获奖的小牛, 而将妻子 一人留在偏僻、少有变化的乡村里。在四天里, 相遇、 相识和相恋的男女主人公, 远离了道德和社会伦理的限 制, 不去担忧家庭责任的束缚, 两个人无忧无虑的相爱。 罗伯特的职业、与众不同的思想和他的善解人意都打动 着弗朗西斯卡的心弦, 重新燃起了她少女时代的梦想。 因为罗伯特的欣赏, 她感觉自己从未那么好看过, 不再 是一个被生活磨灭性格的主妇。而弗朗西斯卡的质朴, 对生活的理解和她那能感动人、也能受到感动的细致心 灵也无疑在四处漂泊的罗伯特心中留下了深深的烙印。 这正是他到处寻找的精神寄托的归宿。在他的眼里, 她 是有 “魔力” 的。这段发生在时空真空里的爱恋是那么 美妙和神奇, 一切都显得那么自然而然。他们两个都进 入到了一个叫做 “咱们” 的 “另一个生命的体内”。爱情 并不遵从我们的想象, 它的神秘在于它的纯洁与纯粹。 这种挚爱让两个人在四天时间里难舍难分, 留下刻骨铭 心的感受。如同小说中 “我希望永远保留这份爱, 我希 望终生都能这样的爱你” 的描述, 这样确切的爱, 一生 只可能发生一次。甚至值得用一辈子时间去等待。

然而没有人可以生活在真空的世界里。后两天时间 里, 两人整日燍守在一起。四天时间转瞬即逝, 弗朗西 斯卡家人即将回归的时候，他们有过一起离开的想法。 弗朗西斯卡甚至想让罗伯特带她走, 马上就走, 带她去 他到过之处, 到世界的另一端。然而弗朗西斯卡最后还 是不愿也不能舍弃家庭, 抛下一切。与罗伯特痛苦的分 手。罗伯特选择了尊重弗朗西斯卡的选择。

因为乡下一成不变生活, 弗朗西斯卡被这个组织化 愈深的世界所影响, 她始终无法摆脱道德准则与社会伦
理施加给她的压力和思想负担。她担心她的出走会使孩 子和理查德在整个温特塞特的闲言碎语中痛苦度过余 下的时间，无法摆脱世俗的眼光影响。她也更担心这样 的思想负担会使自己变成另外一个人, 一个不是罗伯特 现在所爱的女人。

尽管两个人都认为 “在一个混沌不清的宇宙中，这 样明确的事只能出现一次, 不论你活几生几世, 以后永 远不会再现”。但是他们最终依然选择了像两条平行线 一样, 期待能有一天“在遥远的某处相遇”。活着的时候, 属于这个家，但愿死了以后，属于另一个人。

像小说里揭示的一样, 每个人都不是脱离了社会而 存在的, 被道德社会化了的弗兰西斯卡, 最终选择了理 性地处理问题, 将深情藏在自己心底, 继续承担起好母 亲、好妻子的责任。这不仅维护了家庭稳定、社会安宁, 也很好的将那段真挚的、痛彻心扉的感情封存, 让那份 感情永远地真实地活在自己的心中。也正是这份感情, 放弃的诱惑、节制的欲望, 让她感满足, 家庭的甜蜜, 让她有勇气一直留在农场里。

\section{4. 带缺口的杯子}

《廊桥遗梦》中, 作者沃勒提到了带缺口的杯子一 “生活中用惯了带缺口的杯子, 但是这回她要完美无缺 的。”在弗朗西斯卡的家里很难找到两个没有缺口的杯 子, 而她和罗伯特喝白兰地的时候她却执意要找到完美 无缺的杯子。这既隐喻着弗朗西斯卡对完美爱情的执着, 这也是人性的体现, 同时又暗示了现实婚姻本身的不完 美。人生永远不完美, 我们又怎能奢望会遇到完美的伴 侣，成就完美的婚姻。

现实生活中，人们往往会从自己的角度出发，抱怨 伴侣的缺点, 放大生活中的矛盾, 而忽视自身的不足。 试想一下, 即使弗朗西斯卡和罗伯特这对相见恨晚、情 深意切、互相欣赏的恋人放下一切负担, 相拥而去, 但 在爱的激情过后, 他们是否还会一如既往地痴迷于对方, 高歌元进地继续他们的生活呢? 平凡琐碎的生活才是 家庭的主流，作者恰恰是在文中用带缺口的杯子来暗示 婚姻生活中的不完美, 这与人们对完美爱情的追求形成 了强烈的对比。当人们享受浪漫爱情的时候, 往往会对 婚姻抱有十足的幻想, 幻想着一切都会因为情到深处而 水到渠成, 从此 “王子” 和 “公主” 过上童话里那般无 忧无虑、幸福无比的生活。可现实却是残酷的。

小说中也正是因为弗兰西斯卡抱着对美国生活的 美好幻想, 嫁给了丈夫理查德。然而, 婚后的生活却让 她大失所望，她走进了有着鸡毛蒜皮小镇习气的麦迪逊 县, 人们表面上看上去很友好, 可是诗人在那里是不受 欢迎的，这种文化自卑感使得弗朗西斯卡感到孤独。丈 夫忠厚勤劳, 却缺少了浪漫情怀。这个乡下农场日复一 日，没有丝毫波澜的平淡、枯燥、劳累生活将她的激情 消磨殆尽, 变得死气沉沉, 丧失理想, 成为生活的奴隶。 


\section{5. 积极的婚恋观}

《廊桥遗梦》里所要表现的是清醒的、十分理智的 爱情。虽然小说中对婚外恋情有着细致入微的描述, 其 所要凸显的仍然是一种较为正统的维系家庭的主题。男 女主人公相爱后, 没有因为情到深处而丧失理性, 经过 了痛苦的抉择, 选择了封存恋情, 弗兰西丝卡经过再三 考虑, 选择了回归家庭, 责任感战胜了爱情, 这恰恰就 是正统的道德观念的产物。在传统的家庭体系当中, 爱 情并不被认为是婚姻的基础, 亲情和责任在婚姻中占据 着至关重要的地位。

随着美国经济、社会环境的变化, 人们的观念也受 到了一定的冲击, 精神上、伦理上甚至爱情观、婚姻观 都受到了很大的影响, 连麦迪逊这样一个相对封闭的县 也不免要面临着新的思想观念的冲击。罗伯特来到了这 里, 新的思想观念也来了, 这里的人们, 特别是弗兰西 斯卡将何去何从, 也是经历了痛苦的抉择过程。在这中 新旧思想的撞击、爱情与责任、现实与传统的撞击中, 如何把握自我, 树立积极的婚恋观对这个不断发展的社 会和这个社会的每一个个体有着很重要的意义。

小说并没有一味的美化畸形的婚外恋情。有人把婚 姻看成是对情侣伦理道德的规范。一旦双方走进婚姻殿 堂, 人们就应该淡化自己对感情追求的人性需求, 应该 时刻以家庭责任为重。当然也有很多人认为婚姻应该遵 从自己的心灵感受, 随心所欲地对待感情, 当爱情不在 了, 婚姻也应该画上句号。正如弗朗西斯卡的一对儿女。 然而, 作者在小说中给我们启示远非如此。

作品中提到 “所有的婚姻, 所有的固定的关系都有 可能陷入这种惰性。习惯使一切都可以预见, 而这种预 见本身又带来安逸, 这点她也体会到了”。理查德不愿 意, 甚至惧怕生活的改变。他的内心里坚立起沟通的屏 障, 只是习惯用自己对婚姻理解的方式去爱护弗兰西斯 卡。正因为这种惰性让弗兰西斯卡和理查德逐渐失去了 交流, 过着同床异梦的生活。现实中, 这并不是个别现 象。由于社会的高速发展, 组织化的世界使了人与人之 间的关系变得麻木, 人的自然性被压抑, 社会性愈加凸 显。在主流价值观的影响下, 人们越来越注重道德规范 的约束, 也把婚姻当成是爱情的保障, 认为自己或伴侣 的付出理所当然, 从而忽视了对方的感受, 忽视了给对 方所喜欢的生活。积极地经营婚姻并不只是意味着承担 家庭责任, 还要有真诚的沟通, 更积极的体验, 体察并 尊重伴侣的内心所想。如果只是固执地坚持自己的观点, 或者在双方喋喋不休抱怨中生活的夫妻, 是难以维系幸 福的婚姻关系。只有伴侣间彼此的理解、包容和改变会 让爱情保鲜, 而不仅仅是情投意合, 才会让婚姻生活鲜 活起来。

\section{6. 结语}

《廊桥遗梦》是一部以倍受争议的婚外恋情为题材 的小说, 但是小说中男女主人公最后的选择, 甚至包括 弗兰西斯卡一双儿女的抉择, 选择了回归到各自濒临破
碎的家庭之中, 都给出了一个好的示范, 毕竟小说描写 的婚外恋更加地打动人，但结局出乎意料的让内核回归 到家庭, 忠于婚姻, 都指引我们回到积极的婚恋观的起 点。弗朗西斯卡和罗伯特的强烈的情感吸引, 唤醒了人 们心中深藏的对美好感情的期待和共鸣, 然而那仅是

“真空中” 的是花一现, 或者只是仅存于人们脑海中的 幻象而已。当我们回到现实, 理性地面对婚姻生活时, 我们看到的是罗伯特选择远远离去, 弗兰西斯卡选择了 对家庭的坚守。理查德去世前谈到弗兰西斯卡没有完成 的梦想, 面对离婚的弗朗西斯卡的儿女在体会母亲的心 路历程后, 也开始重新思考他们婚姻生活。这描绘了出 作者乃至整个社会所期待的家庭回归，社会安定的景象。 这些都源于人与人之间的建立在理解基础上的尊重和 包容。

渴望真挚的感情本是人性的体现, 我们对爱情和婚 姻有很多美丽的构想, 希望拥有天长地久的感情, 两情 相悦、长相厮守的伴侣。然而, 人们生活在一个组织体 系越来越严格的世界里, 一切变得更加有秩序, 秩序在 带来安逸的同时也带来了惰性, 还有愈加麻木的人际关 系。而 “廊桥” 的寓意恰恰在于积极搭建人们心中的沟 通的桥梁, 以爱人喜欢的方式去爱和付出, 学会感恩, 懂得包容，去努力拥有自己 “翩翩起舞的天地”。

\section{REFERENCES}

[1] Deng J W. (2000) The cultural value orientation of The Bridges of Madison County, Journal of Chengdu University (Social Science), (04): 45-48.

[2] Hong S X. (2013) Middle aged women's "lost dream", Anhui Wenxue, (05): 29-30.

[3] Lu J, Zhao C X. (2013) An analysis of the feminist thoughts in The Bridges of Madison County, The Great Wall, (06): 181-182.

[4] Lu W S. (2008) On the Ethical values and the socialization of man in The Bridges of Madison County, Journal of Jilin Normal University of Engineering Technology, (12): 27-29.

[5] Wang S N. (2006) The bewildering dream-To interpret The Bridges of Madison County from the perspective of feminism, Journal of Shaoguan University, (11): 34-37.

[6] Wang S N. (2019) The bewildering dream-To analyze the ecological female consciousness in The Bridges of Madison County, The Journal of Shandong Agriculture and Engineering University, (10): 85-86. 